\title{
Prevalence and Disability Induced by Acne Vulgaris among Adolescent Students at Secondary Schools in Assiut City
}

\author{
Amel Abd El Shafy Mohamed', Hoda Diab Fahmy ${ }^{2}$, Neama Mohamed El-Magrabi ${ }^{3}$, Naglaa Saad Abd El Aty ${ }^{4}$. \\ 1. Assistance Lecturer of Community Health Nursing, Faculty Of Nursing, Assiut University, Egypt. \\ 2. Professor of Community Health Nursing, Faculty Of Nursing, Assiut University, Egypt. \\ 3. Assistant Professor of Community Health Nursing, Faculty Of Nursing, Assiut University, Egypt. \\ 4. Assistant Professor of Community Health Nursing, Faculty Of Nursing, Assiut University, Egypt.
}

\begin{abstract}
Background: Acne vulgaris is one of the commonest skin disorders which dermatologists have to treat, mainly affect adolescents. It has been found to have a significant impact on their psychological status, The study aimed to identify the prevalence of acne vulgaris among adolescents students and the disability induced by acne vulgaris on them .Subjects and methods: descriptive research cross sectional design was used. It was conducted in four secondary schools at Assiut city. The total study sample was 1026 students which was selected randomly. The study included two tools: first tool was self-administered structure questionnaire, which included two parts, first part was some demographic data of studied students and the second part was about acne vulgaris. The second tool was Acne Disability Index. Results: It was found that $67 \%$ of the studied students were female and the mean age \pm SD was $16.37 \pm 1.18$. The prevalence of acne in studied students was $60.5 \%$. Also, $63.3 \%$ of studied adolescent students had mild disability effect Conclusion: Acne vulgaris is more prevalent among studied students .There was statistically significant difference between Acne Disability Index and students' age and more than three fifths of studied adolescent students had mild disability effect from acne Recommendations: school health nurses should be attended the educational programs about acne because they are most contact and deal with the students.
\end{abstract}

\section{Keywords: Acne vulgaris, Prevalence \& Disability.}

\section{Introduction}

Acne vulgaris is considered a major problem of adolescents. It is easily recognizable and well known. Also it is physiological process but it is considered a disease due to its inflammatory process. It results in disfigurement on the face, which is psychologically and socially the most important site in the body. This disfigurement results in a greater psychological problem than other chronic diseases (Hinge et al., 2014).

Acne vulgaris is a long term skin condition presented by shapes of blackheads, whiteheads, pimples, greasy skin and scars may be formed. Moreover, it is a disorder of the hair follicles in the face, chest, and back that affects almost all males and females during puberty. It is not caused by bacteria, although bacteria play a role in its development (Kartheepan et al., 2015).

Acne may be known as hormonal acne because of testosterone hormone which is considered one of a major causative factor. During puberty testosterone levels increased. This hormone causes male development in boys and gives muscle and bone strength in girls. The hormone cause increase sebum production of hair follicles. This is because the glands that secrete the oil are sensitive to testosterone. Also hormonal changes during pregnancy or the menstrual cycle can also trigger acne (Bettoli et al., 2015).

Acne is associated with psychological problems There is no single disease which causes more psychological problems, more maladjustment between parents and children, more feeling of insecurity and feeling of inferiority and greater sums of psychological suffering than does acne vulgaris. Although patients with acne are not affected in terms of general health status, morbidity, or life span (AlShidhani et al., 2015).

Adolescent stage is a complex life cycle characterized by many biological, psychological, physical and social changes. It is a labile stage where development of self-esteem occurs. During late adolescence high self-esteem is especially significant, when major life choices are made . Experiencing high self-esteem serves as a protective factor in coping with new life changes. Whereas low self-esteem which accompanied by acne is associated with anxiety, depression, and increased reports of general psychiatric problems (Alharithy, 2011).

Worldwide, the prevalence of acne vulgaris is high. Community-based studies conducted within the last decade have reported prevalence rates from $49.8 \%$ to $93.2 \%$. Acne vulgaris occurs in all ethnicities and races, and mainly affects adolescents (Global Burden of Diseases, 2013). 
Acne prevention measures dependent on the successful management of modifiable risk factors, such as underlying systemic diseases and lifestyle factors. There are several treatments are available for acne, but guidelines suffer from a lack of data to make evidence-based recommendations. In addition, the complex combination treatment needed to target different aspects of acne pathophysiology lead to poor adherence, which undermines treatment success (Tuchayi et al., 2015).

The school nurse provides health education by providing health information to individual students and groups of students through health education, science, and other classes. The school nurse assists on health education curriculum development teams and may also provide programs for staff, families, and the community (American Academy of Pediatric , 2016).

\section{Significant of the study}

Acne vulgaris is often misunderstood as a simple puberty related condition by common people and even medical community, while scientific evidence revealed that acne effects patients more than a simple dermatologic disease. It has been observed that social and psychological impacts of acne are sometimes so complicated that cause serious problems in patients' body image, self-esteem, and socialization and even may lead to feel of anger (Safizadeh et al,2012).

In Egypt, detailed studies on the magnitude of the problem regarding prevalence, sex distribution, probable associated risk factors and treatment patterns are lacking. The prevalence of acne vulgaris in the study conducted by El-Khateeb et al, 2014 under the title of prevalence, beliefs, patients' attitudes, severity and impact on quality of life in Egypt reported that the prevalence of acne among the sample was $54.2 \%$.

\section{Aim of the study}

To identify the prevalence of acne vulgaris among adolescents students and the disability induced by acne vulgaris on them.

\section{Research questions:}

1. What is the prevalence of acne vulgaris among adolescent students?

2. Is acne vulgaris has disability effect on adolescent students?

\section{Subjects \& method \\ Research design}

Descriptive research, cross sectional design was used in this study.

\section{Setting of the study}

The study was carried out in four secondary schools, El Moushir Ahmed Ismail secondary school for boys, El Khayat secondary school for girls and Tahrir language school for boys and girls and Abd El Moneim Riad commercial secondary school at Assiut city, which were selected randomly.

\section{Sampling}

Multi stage random sample was used in this study, Assiut city includes 29 secondary schools, 12 general governmental secondary schools and 17 technical secondary schools, four schools were selected randomly. The sample was detected by taking $25 \%$ from the total number of each school, which was selected randomly.

\begin{tabular}{|l|c|c|c|}
\hline \multicolumn{1}{|c|}{ School name } & $\begin{array}{c}\text { Total } \\
\text { number of } \\
\text { students }\end{array}$ & $\begin{array}{c}\text { *Percentage } \\
\text { of sample }\end{array}$ & $\begin{array}{c}\text { Studied } \\
\text { students }\end{array}$ \\
\hline $\begin{array}{l}\text { El Moushir Ahmed } \\
\text { Ismail secondary School }\end{array}$ & 1104 & $26.88 \%$ & 276 \\
\hline $\begin{array}{l}\text { El Khayat Secondary } \\
\text { School For Girls }\end{array}$ & 1218 & $29.66 \%$ & 304 \\
\hline Tahrir Language School & 134 & $3.26 \%$ & 33 \\
\hline $\begin{array}{l}\text { Abdel Moneim Riad } \\
\text { Commercial secondary } \\
\text { School }\end{array}$ & 1650 & $40.20 \%$ & 413 \\
\hline Total & 4106 & $100 \%$ & 1026 \\
\hline
\end{tabular}

* Percentage of sample according to total number of students in each school

After calculation the sample was 1026 adolescent students who subjected for assessment. It was observed that 621 students out of the previous total number of studied sample (1026 students) had acne vulgaris.

Tools of the study: The study was included two tools.

Tool I

Self-administered questionnaire was developed by the research team for data collection. It was based on review of relevant literatures. This questionnaire was included two parts, the first part included some demographic characteristics of adolescent students as ( age, sex, academic year, fathers' education, fathers' occupation, mothers' education, mothers' occupation) The second part was about acne vulgaris as having acne , medical history such as family history of acne vulgaris and number of family members affected by acne vulgaris, duration, places, symptoms and treatment of acne vulgaris.

\section{Tool II}

The Cardiff Acne vulgaris Disability Index (CADI).It is a disease-specific questionnaire measuring disability induced by acne vulgaris.

It was comprised of five questions. The first four questions were related to the feelings of aggression, frustration, interference with social life, avoidance of public changing facilities and appearance of skin. Fifth question gave indication of how bad the acne vulgaris was . 


\section{Scoring system}

The response to each of five questions was scored from 0 to 3, with a total maximum score of 15 grades, a minimum score of 0 grade. The higher score meaned that more impaired in affected individuals.

- 0-5 translated to mild effect

- 6-10 indicated moderate effect

- 11-15 demonstrated severe effect (Yap ,2012\& Law et al., 2009).

\section{Validity of the tools:}

The tools were transferred to Arabic language and reviewed to ascertain their validity by seven experts in medical and nursing sciences, who reviewed the instrument for clarity, relevance, comprehensiveness, understanding and applicability

Reliability: Reliability of tool II was assessed using alpha-cron-bach test to test the internal consistency

$$
\text { r1 }=0.8543 \text {. }
$$

\section{Ethical considerations}

The students were recruited to the study informed about the objectives of the study and they are free to refuse participation. A verbal consent obtained from the students. Confidentiality of obtained information was assured as the obtained information was used only for the purpose of the study.

\section{Pilot study}

Pilot study was carried out before starting of data collection on $10 \%$ of adolescent students; who included in the sample. It aimed to test the clarity of the tools and estimate the required time to fill the questionnaire.

\section{Field work}

The data was collected from October 2014 to the end of December 2014.The assessment was done for 1026 adolescent students. While disability of acne was measured with the Acne Disability index which was done for 621 adolescent students who had acne.

The researcher met the students in their classes. Selfadministered questionnaire filled by the students themselves. The researcher was presented during filling the questionnaire to answer any questions and for further explanation on the questionnaire. The duration was (20-30) minutes which is the time of each school period. The data was collected in (two day/ week).At each school the pre calculation percentage of students were met .

The data collection was taken three months .Every week about (80-90) sheets were finished.The researcher begin with Tahrir Language School and when finished went to others schools and finished by Abdel Moneim Riad Commercial secondary school. There was variation in time between schools according the schedule of each one and available time. The researcher began data entry after data collection at the end of December 2014.

\section{Statistical Analysis}

The data obtained were reviewed, prepared for computer entry, coded, analyzed and tabulated to evaluate the differences between the groups under the study. Descriptive statistics (i.e., frequencies, mean and standard deviation) was done using computer program SPSS version 19. Chi-square test was used. The test is considered significant when $\mathrm{P}$-values were less than 0.05 or $(\mathrm{P}<0.05)$. 


\section{Results}

Table (1):Distribution of the studied adolescent students regarding to their demographic characteristics in Assiut city, $2015 \mathrm{n}=(\mathbf{1 0 2 6})$.

\begin{tabular}{|c|c|c|}
\hline Items & $\begin{array}{c}\text { No }(n= \\
1026)\end{array}$ & $\%$ \\
\hline \multicolumn{3}{|l|}{ School type } \\
\hline General secondary school & 612 & 59.6 \\
\hline Secondary technical school & 414 & 40.4 \\
\hline \multicolumn{3}{|l|}{ Adolescent students' age } \\
\hline $15-16$ years & 617 & 60.1 \\
\hline$>16$ years & 409 & 39.9 \\
\hline Mean \pm SD (Range) & & $16.37 \pm 1.18(15.0-20.0)$ \\
\hline \multicolumn{3}{|l|}{ Adolescent students' sex } \\
\hline Male & 339 & 33.0 \\
\hline Female & 687 & 67.0 \\
\hline \multicolumn{3}{|l|}{ Academic years } \\
\hline First & 493 & 48.1 \\
\hline Second & 297 & 28.9 \\
\hline Third & 145 & 14.1 \\
\hline Fourth & 49 & 11.8 \\
\hline Fifth & 42 & 10.1 \\
\hline \multicolumn{3}{|l|}{ Fathers' education } \\
\hline Illiterate & 19 & 1.9 \\
\hline Read \& write & 83 & 8.1 \\
\hline Basic education & 104 & 10.1 \\
\hline Secondary & 273 & 26.6 \\
\hline University or more & 547 & 53.3 \\
\hline \multicolumn{3}{|l|}{ Fathers' occupation } \\
\hline Farmer & 28 & 2.7 \\
\hline Worker & 120 & 11.7 \\
\hline Technical worker & 116 & 11.3 \\
\hline Free business & 85 & 8.3 \\
\hline Governmental employee & 565 & 55.1 \\
\hline Retired & 56 & 5.5 \\
\hline Unemployed & 33 & 3.2 \\
\hline Died & 23 & 2.2 \\
\hline \multicolumn{3}{|l|}{ Mothers' education } \\
\hline Illiterate & 55 & 5.4 \\
\hline Read \& write & 73 & 7.1 \\
\hline Basic education & 90 & 8.8 \\
\hline Secondary & 345 & 33.6 \\
\hline University or more & 463 & 45.1 \\
\hline \multicolumn{3}{|l|}{ Mothers' occupation } \\
\hline Working & 404 & 39.4 \\
\hline Housewife & 620 & 60.4 \\
\hline Died & 2 & 0.2 \\
\hline
\end{tabular}




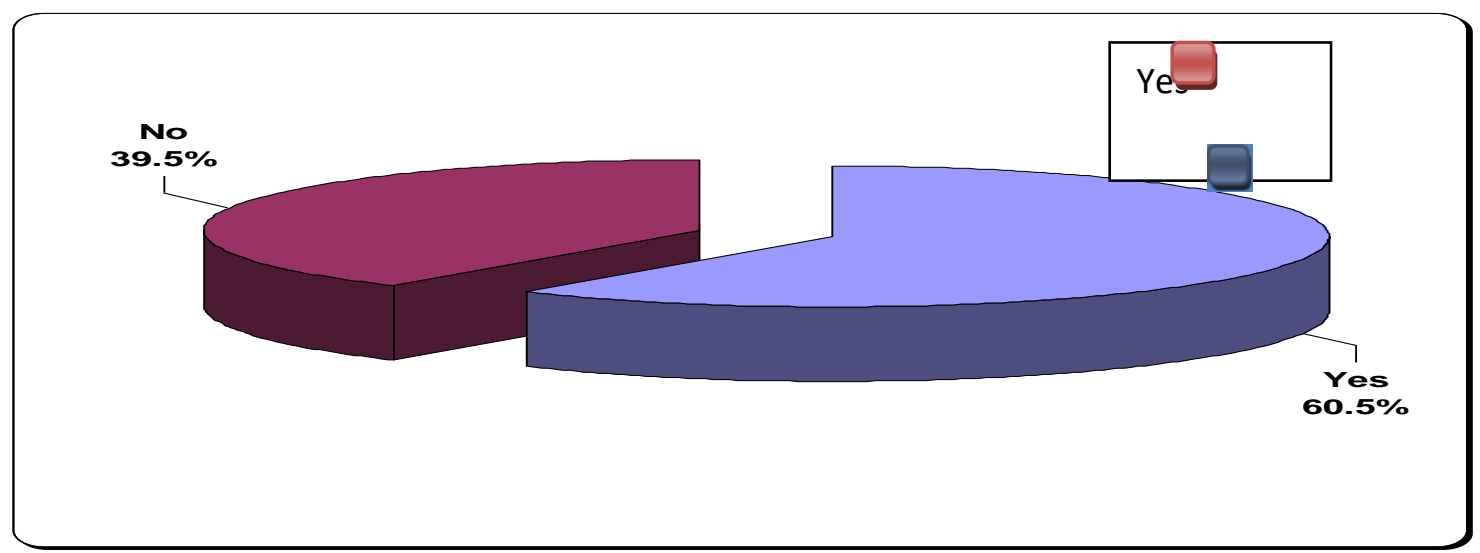

Figure (1): Distribution of the studied adolescent students regarding to their suffering from acne vulgaris in Assiut city, 2015 (n=1026)

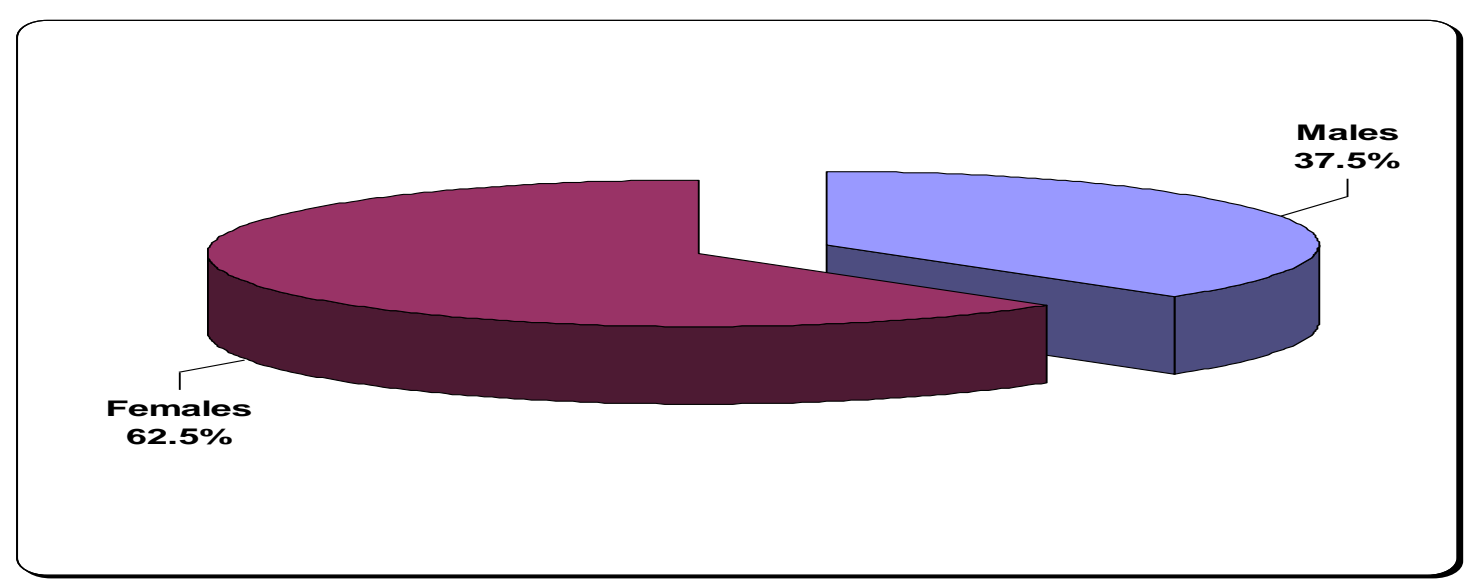

Figure (2): Distribution of the sex of studied adolescent students with acne in Assiut city, 2015 (n=621)

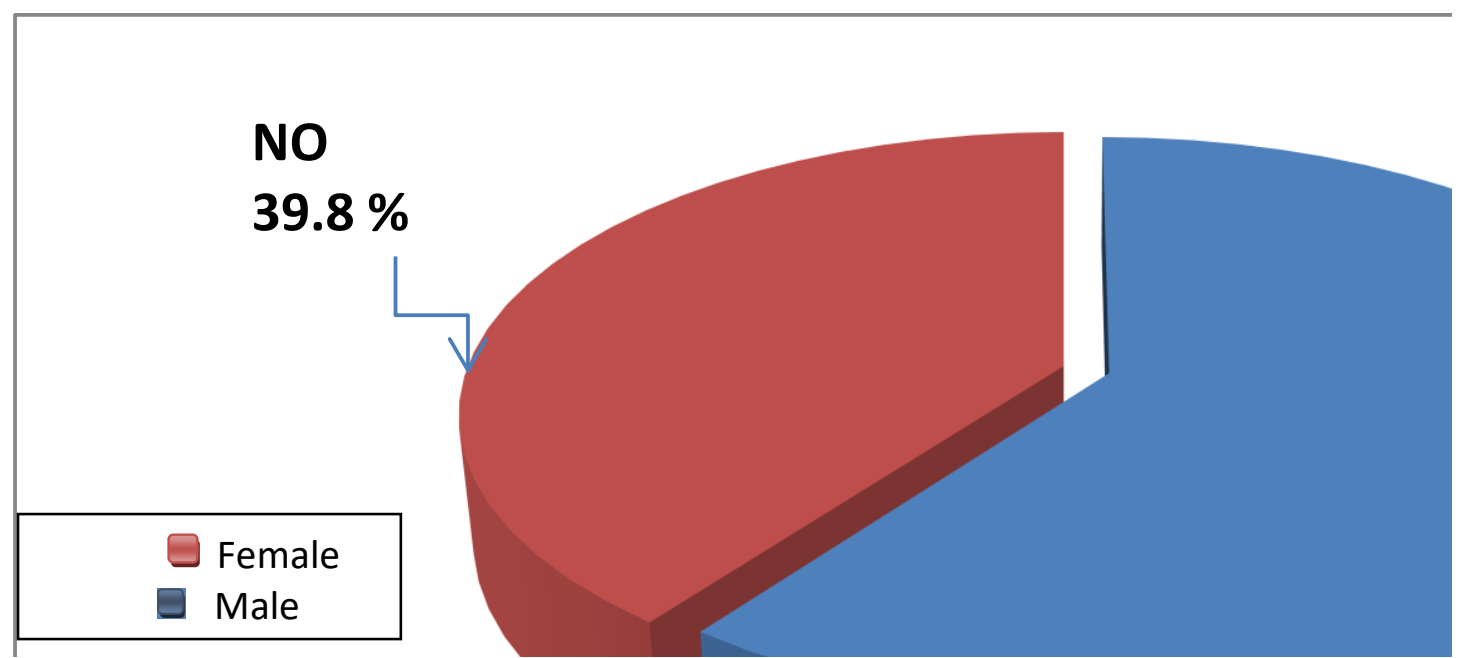

Figure (3): Distribution of studied adolescent students with acne according to their family history of acne in Assiut city, 2015 (n=621) 
Table (2): Distribution of studied adolescent students with acne according to their suffering from acne in Assiut city, 2015.

\begin{tabular}{|c|c|c|}
\hline Items & No. $(n=621)$ & $\%$ \\
\hline \multicolumn{3}{|l|}{ Duration of suffering } \\
\hline$<1$ year & 312 & 50.2 \\
\hline $1-5$ years & 203 & 32.7 \\
\hline$>5$ years & 106 & 17.1 \\
\hline Mean \pm SD (Range) & \multicolumn{2}{|c|}{$3.53 \pm 1.46(1 \mathrm{~m}-15 \mathrm{y})$} \\
\hline \multicolumn{3}{|c|}{ Places of appearance of acne vulgaris: \# } \\
\hline Face & 511 & 82.3 \\
\hline Back & 154 & 24.8 \\
\hline Shoulders & 62 & 10.0 \\
\hline Chest & 46 & 7.4 \\
\hline Neck & 41 & 6.6 \\
\hline \multicolumn{3}{|l|}{ Symptoms of acne vulgaris: \# } \\
\hline Itching & 238 & 38.3 \\
\hline Sense of pain & 167 & 26.9 \\
\hline Pimples only & 132 & 21.3 \\
\hline Burning at the affected site & 112 & 18.0 \\
\hline \multicolumn{3}{|l|}{ Treatment used } \\
\hline Yes & 278 & 44.8 \\
\hline No & 343 & 55.2 \\
\hline \multicolumn{3}{|l|}{ Types of treatment used : $(\mathrm{N}=278) \#$} \\
\hline Antibiotics & 263 & 94.6 \\
\hline Use natural herbs & 91 & 32.7 \\
\hline Hormonal treatment & 13 & 4.7 \\
\hline Cortisone treatment & 2 & 0.7 \\
\hline
\end{tabular}

\# More than one answer

Table (3): Distribution of the studied adolescent students regarding to Acne Disability Index in Assiut city, 2015.

\begin{tabular}{|l|c|c|}
\hline \multicolumn{1}{|c|}{ Items } & No. $(\mathbf{n = 6 2 1})$ & \% \\
\hline As a result of having acne vulgaris, you were aggressive, frustrated or embarrassed & 10.6 \\
\hline Very much indeed & 66 & 13.1 \\
\hline A lot & 81 & 38.8 \\
\hline A little & 241 & 37.5 \\
\hline Not at all & 233 & 7.1 \\
\hline $\begin{array}{l}\text { Acne vulgaris interfered with your daily social life, social events or relationships with members of the } \\
\text { opposite students' sex }\end{array}$ & 44 & 19.5 \\
\hline Severely, affecting all activities & 121 & 26.6 \\
\hline Moderately, in most activities & 165 & 46.8 \\
\hline Occasionally or in only some activities & 291 & 3.9 \\
\hline Not at all & 24 & 5.2 \\
\hline You avoided public changing facilities or wearing swimming costumes because of your acne vulgaris \\
\hline All of time & 32 & 30.6 \\
\hline Most of time & 190 & 60.4 \\
\hline Occasionally & 375 & 13.5 \\
\hline Not at all & 84 & 17.7 \\
\hline Describe your feelings about the appearance of your skin & 110 & \\
\hline Very depressed and miserable & \multicolumn{2}{|c|}{} \\
\hline Usually concerned & \multicolumn{1}{|c|}{} \\
\hline
\end{tabular}




\begin{tabular}{|l|c|c|}
\hline \multicolumn{1}{|c|}{ Items } & No. (n=621) & \% \\
\hline Occasionally concerned & 268 & 43.2 \\
\hline Not bothered & 159 & 25.6 \\
\hline Indicate the bad you think your acne vulgaris is now & \multicolumn{2}{|c|}{} \\
\hline The worst it could possibly be & 56 & 9.0 \\
\hline A major problem & 154 & 24.8 \\
\hline A minor problem & 290 & 46.7 \\
\hline Not a problem & 121 & 19.5 \\
\hline
\end{tabular}

Table (4 ): Relationship between demographic characteristics of studied adolescent students and Acne Disability Index in Assiut city, 2015.

\begin{tabular}{|c|c|c|c|c|c|c|c|c|}
\hline \multirow{3}{*}{ Items $(n=621)$} & \multicolumn{6}{|c|}{ Acne Disability Idex } & \multirow{3}{*}{$\mathbf{X}^{2}$} & \multirow{3}{*}{ P-value } \\
\hline & \multicolumn{2}{|c|}{$\begin{array}{c}\text { Mild } \\
(n=393)\end{array}$} & \multicolumn{2}{|c|}{$\begin{array}{c}\text { Moderate } \\
(n=188)\end{array}$} & \multicolumn{2}{|c|}{$\begin{array}{l}\text { Severe } \\
(n=40)\end{array}$} & & \\
\hline & No. & $\%$ & No. & $\%$ & No. & $\%$ & & \\
\hline \multicolumn{7}{|l|}{ School type } & \multirow{3}{*}{15.73} & \multirow{3}{*}{$0.000^{*}$} \\
\hline General Secondary School & 298 & 75.8 & 105 & 55.9 & 26 & 65.0 & & \\
\hline Technical Secondary School & 95 & 24.2 & 83 & 44.1 & 14 & 35.0 & & \\
\hline \multicolumn{7}{|l|}{ Adolescent students' age } & \multirow{3}{*}{6.02} & \multirow{3}{*}{$0.049 *$} \\
\hline $15-16$ years & 240 & 61.1 & 104 & 55.3 & 17 & 42.5 & & \\
\hline$>16$ years & 153 & 38.9 & 84 & 44.7 & 23 & 57.5 & & \\
\hline \multicolumn{7}{|l|}{ Adolescent students' sex } & \multirow{3}{*}{4.84} & \multirow{3}{*}{0.089} \\
\hline Male & 160 & 40.7 & 59 & 31.4 & 14 & 35.0 & & \\
\hline Female & 233 & 59.3 & 129 & 68.6 & 26 & 65.0 & & \\
\hline \multicolumn{7}{|l|}{ Academic years } & \multirow{6}{*}{9.93} & \multirow{6}{*}{0.270} \\
\hline First & 191 & 48.6 & 85 & 45.2 & 18 & 45.0 & & \\
\hline Second & 111 & 28.2 & 57 & 30.3 & 13 & 32.5 & & \\
\hline Third & 72 & 18.3 & 30 & 16.0 & 4 & 10.0 & & \\
\hline Fourth & 9 & 2.3 & 5 & 2.7 & 3 & 7.5 & & \\
\hline Fifth & 10 & 2.5 & 11 & 5.9 & 2 & 5.0 & & \\
\hline \multicolumn{7}{|l|}{ Fathers' education } & \multirow{6}{*}{10.73} & \multirow{6}{*}{0.218} \\
\hline Illiterate & 7 & 1.8 & 1 & 0.5 & 0 & 0.0 & & \\
\hline Read \& write & 25 & 6.4 & 22 & 11.7 & 2 & 5.0 & & \\
\hline Basic education & 33 & 8.4 & 20 & 10.6 & 6 & 15.0 & & \\
\hline Secondary & 97 & 24.7 & 49 & 26.1 & 9 & 22.5 & & \\
\hline High education & 231 & 58.8 & 96 & 51.1 & 23 & 57.5 & & \\
\hline \multicolumn{7}{|l|}{ Mothers' education } & \multirow{6}{*}{9.38} & \multirow{6}{*}{0.311} \\
\hline Illiterate & 22 & 5.6 & 10 & 5.3 & 2 & 5.0 & & \\
\hline Read \& write & 27 & 6.9 & 15 & 8.0 & 4 & 10.0 & & \\
\hline Basic education & 28 & 7.1 & 21 & 11.2 & 2 & 5.0 & & \\
\hline Secondary & 111 & 28.2 & 60 & 31.9 & 17 & 42.5 & & \\
\hline High education & 205 & 52.2 & 82 & 43.6 & 15 & 37.5 & & \\
\hline \multicolumn{7}{|l|}{ Mothers' occupation } & \multirow{3}{*}{11.72} & \multirow{3}{*}{$0.003 *$} \\
\hline Worker & 195 & 49.6 & 65 & 34.6 & 17 & 42.5 & & \\
\hline Housewife & 198 & 50.4 & 123 & 65.4 & 23 & 57.5 & & \\
\hline
\end{tabular}

* There is significant difference $(P<0.05)$

$X^{2}$ Chi-square test 


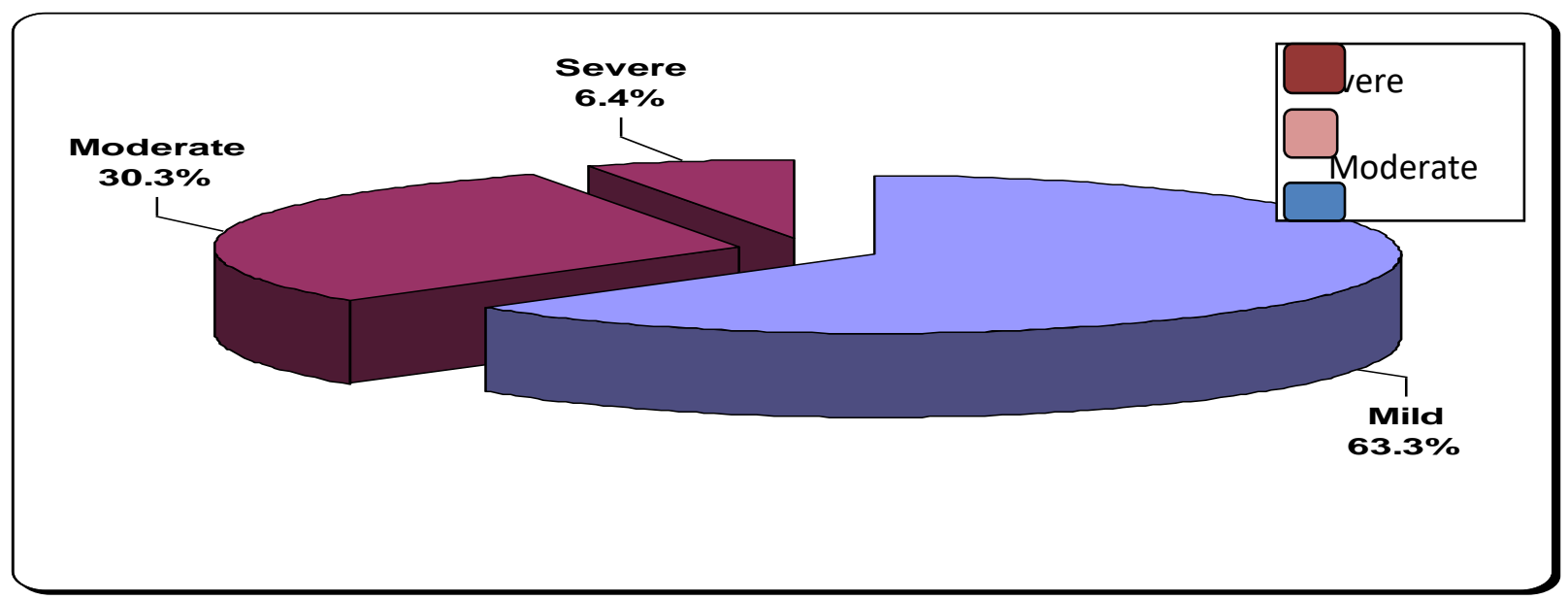

Figure (4): Distribution of the studied adolescent students according to the total score of Acne Disability Index in Assiut city, $2015(n=621)$

Table (1): Shows distribution of the studied adolescent students regarding to their demographic characteristics. Concerning adolescent students' age, it was showed that $60.1 \%$ of adolescent students, their age ranged from (15-16 years), while $39.9 \%$ of them their age was more than 16 years .The Mean age $\pm \mathrm{SD}$ was $16.37 \pm 1.18$.

Concerning adolescent students' sex, it was found that $67 \%$ of adolescent students were female. The table illustrates that $53.3 \%$ of students' fathers and $45.1 \%$ of students' mothers had university education, while $1.9 \%$ and $5.4 \%$ of students' fathers and students' mothers were illiterate respectively. Also, it was observed that more than $60.4 \%$ of students' mothers were housewives.

Figure (1): View distribution of the studied adolescent students regarding their suffering from acne vulgaris. It was found that $60.5 \%$ of studied adolescent students suffering from acne vulgaris, while $39.5 \%$ of them didn't suffer.

Figure (2): Shows distribution of the sex of studied adolescent students with acne. It was found that $62.5 \%$ of the studied adolescent students suffer from acne were females and $37.5 \%$ of them were males.

Figure (3): Shows distribution of studied adolescent students with acne according to their family history of acne. It was found that $60.2 \%$ of studied students had family history of acne vulgaris.

Table (2): Shows distribution of studied adolescent students who suffering from acne according to their history. Regarding family history of acne vulgaris, it was cleared that $60.2 \%$ of adolescent students had family history of acne vulgaris.

As regard site of acne vulgaris appearance, it was noticed that $82.3 \%$ of studied adolescent students had acne vulgaris in their faces. Also, this table presents that $38.3 \%$ of adolescent students experienced itching as symptoms of acne vulgaris.
Concerning the type of treatment used, it was observed $55.2 \%$ of studied adolescent students suffering from acne didn't use any treatment.

Table (3): Shows distribution of the studied adolescent students regarding to Acne Disability Index. It was observed that only $10.6 \%$ of studied adolescent students very much indeed were aggressive , frustrated or embarrassed .Also $46.8 \%$ of studied adolescent students reported that acne vulgaris didn't interfered with their daily social life, social events or relationships with members of the opposite sex.

Concerning avoidance of public changing facilities or wearing swimming, it was releaved that $30.6 \%$ of studied adolescent students had occasionally effect. In addition, this table shows that $43.2 \%$ of studied adolescent students were occasionally concerned about appearance of their skin. Finally, it was observed that $46.7 \%$ of studied adolescent students considered acne vulgaris as minor problem. While $19.5 \%$ of them didn't consider acne vulgaris as a problem.

Table (4): Shows relationship between some demographic data of studied adolescent students with acne vulgaris and Acne Disability Index. This table observes that there is significant difference between Acne Disability Index and school type, adolescent students' age and mothers' occupation, $\mathrm{P}=0.000$, $0.049 \& 0.003$ respectively.

In difference, there is not significant difference between Acne Disability Index and adolescent students' sex, adolescent students' age, academic year, fathers' education and mothers' education, $\mathrm{P}=0.089$, $0.270,0.218 \& 0.311$ respectively.

Figure (4): Illustrates distribution of studied adolescent students' according to the total score of Acne Disability Index. It was found that $63.3 \%$ of 
studied adolescent students had mild effect and only $6.4 \%$ of them had severe effect.

\section{Discussion}

Adolescents are psychologically vulnerable. They are sensitive to modifications in their bodies and appearance. Acne commonly affects young people at a time when they are undergoing maximum psychological, social and physical change. Between $30 \%-50 \%$ of adolescents experience psychological difficulties associated with their acne. Although the interaction is complex it can be associated with developmental issues of body image, socialization and sexuality (Al-Shidhani et al., 2015 \& Durai \& Nair, 2015).

The current study observed that slightly more than three fifth of studied students had acne and about half of them suffered from acne for less than one year ago. In the researcher point of view, these results may be explained by that the studied sample was from teenage where acne is most common during this age. These results agreed with (Sultana, 2012) who carried out study in Dhaka city , Bangladesh about knowledge on acne vulgaris on adolescent girls and found that $62.8 \%$ of students had acne. Also, these results were in the same line with (El-Khateeb et al., 2014) who reported that the prevalence of acne among the sample was 54.2\%.In addition, these results agreed with (Suvirya et al., 2016) who conducted study in India for assessment of selfmedication practices among medical students in acne vulgaris. They reported that the prevalence of acne vulgaris was $55.9 \%$.

According to students' family history of acne, the current study cleared that slightly more than three fifths of studied students had family history of acne . The reason for these findings is consistent with the other studies as (Armand et al., 2015 \& Bagatin et al.,2014) and probably related to genetic factors.

These results were in the same line with (Saker et al, 2015) who carried out a study for evaluation of psychiatric morbidity and quality of life for acne and found that family history of acne was present among $58.3 \%$ of studied people.

Moreover, (Armand et al., 2015) reported that students with family history of acne were $58.3 \%$. In addition, these results were agreed with Bagatin et al., (2014) who showed that about half of the adolescents students reported a family history of acne in mothers or fathers.

On the other hand, these results disagreed with Peric' et al., (2013) who showed that $44.7 \%$ of studied students had family history and Durai \& Nair, (2015) who reported that $21.4 \%$ of individuals had a positive family history. Also, El badry, (2009) reported that family history found to be positive in $43 \%$ of adolescents.

As regard to duration of having acne, the results of the present study releaved that more than half of the studied students reported that they had acne from less than one year. It may be explained by slightly less than half of studied students were in the first secondary year.

These results agreed with (Peric' et al., 2013) who found that $51.4 \%$ of sample had acne less than one year.

In contrast, the study conducted in Japanese showed that $14.7 \%$ of adolescents estimated their acne had first started between six months and one year ago

(Kubota et al., 2010). Also, these results disagreed with Hazarika \& Rajaprabha,2016 who conducted a study about assessment of life quality among patients with acne vulgaris in a suburban population and reported that $42 \%$ of studied sample had acne for less than 6 months.

Also, another study conducted by Samanthula \& Kodali, (2013) who carried out a study in South India about acne and quality of life and found that $60.04 \%$ of studied participants had acne for more than one year.

With regard site of acne appearance, the present study noticed that more than four fifth of studied students had acne in their face While about one quarter of them had acne in their back This result may be explained by the face is the site which exposed to surface and easily clogging the pores of the skin by air draft and sunlight. In addition to that proliferation of sebaceous glands in these areas of skin.

These results agreed with (Bagatin et al., 2014 \& Durai \& Nair, 2015) who reported that the majority of adolescents had acne in face. In addition, these results agreed with Tasoula et al., (2012) who conduct a study in Greece to assess the impact of acne vulgaris on quality of life and psychic health in young adolescents and found that the prevalence of facial acne was $89.1 \%$ and acne in the back was $41.3 \%$.

Moreover, these results were in the same line with Saker et al., (2015) who reported that the face was $79 \%$, the prevailing site of lesions. Also, Armand et al., (2015) showed that $79 \%$ of students had acne in their faces.

Concerning acne treatment used, the results of present study observed that more than half of studied students didn't use any thing for acne treatment, while the majority of students used antibiotics and slightly less than one third of them used natural herbs for treatment. From the researcher point of view the reason for these results may be due to inadequate skin 
health education and misinformation which contribute to the reluctance to seek treatment.

These results agreed with Steylaerts, (2014) who reported that $42.6 \%$ of students with acne didn't used acne treatment and disagreed with the present study on $31.9 \%$ of students used oral antibiotics for treatment.

In contrast, these results weren't in the same line with Moneam et al., (2016) who conduct study to assess the prevalence and factor affecting acne vulgaris among university students at Ajman, United Arab Emirates and reported that $6.7 \%$ of students used herbal treatment in their acne treatment.Also, These results disagreement with Peric' et al., (2013) who observed that $70.1 \%$ of students received treatment for acne .

The results of the present study found that more than three fifths of studied students had mild effect, while slightly less than one third of them had moderate effect and finally only $6.4 \%$ of studied students had severe effect. The explanation of these results may be due to some students didn't considered acne is a problem and it is normal event that take time and disappear.

These results were in the same line with El-Hamd et al., (2017) who reported that 53\% of students reported mild effect , followed by $41 \%$ of them had moderate effect and only $6 \%$ of them had severe effect. In addition, these results supported by Yap, (2012) who reported that $59.5 \%$ of studied sample had mild effect, while, $28.5 \%$ of them had moderate effect and $12 \%$ of them had severe effect.

These results were in contrast with Shahzad et al., (2011) who conducted study in Pakistan about frequency and psychosocial impact of acne on university and college students and they reported that $81.3 \%$ of studied students had mild effect, while, $15.5 \%$ of them had moderate effect and only $3.2 \%$ of them had sever effect .

Moreover, these results disagreed with Durai \& Nair, (2015) Who releaved that $48.6 \%$ of studied sample had low effect, while, $38.6 \%$ of them had medium effect was and $12.9 \%$ of them had high effect.

The present study showed that there was no association between Acne Disability Index and students' gender, The explanation for that may be due to acne affects similarly on both sexes. These results were in the same line with (Noorbala et al., 2013 \& Hanisah et al., 2009) who reported that there was no significant difference in the Acne Disability Index score between the gender.

The present study showed that there was association between Acne Disability Index and students' age .The explanation of this result is consistent with relevant literature which mentioned that the acne increases with age. due to These results were in the same line with (Durai \& Nair, 2015) who reported that there was significantly associated between age of studied sample and Acne Disability Index.

\section{Conclusion}

based on the results of the present study it can be concluded that slightly more than three fifths of studied adolescent students suffering from acne vulgaris. More than three of studied adolescent students had mild disability effect from acne. There was statistically significant difference between Acne disability Index and students' age.

\section{Recommendations}

based on the results of the present study it can be recommended that:

- The students require health education class awareness should be included information about skin diseases especially acne and skin care, how to deal with disease, good dietary habits and how to prevent its occurrence.

- Posters about skin care, how to control and prevent it should be distributed in the schools especially secondary schools.

- Future researches about acne prevention and control are required.

\section{References}

1. Alharithy R., (2011): Adolescent's acne: Scarring inside out, Journal of the Saudi Society of Dermatology \& Dermatologic Surgery (2011) 15, 43-46.

2. Al-Shidhani A., Al-Rashdi S., Al-Habsi H., \& Rizvi S., (2015): Impact of Acne on Quality of Life of Students at Sultan Qaboos University, Oman Med J. 2015 Jan; 30(1): 42-47.

3. American Academy of Pediatrics (AAP) (2016): Role of the school nurse in providing school health services (Policy Statement). Pediatrics; originally published online May 23, 2016.1542/peds.2016-0852.

4. Armand K., Richie N., Defo D., Bissek Z., \& Cecile A., (2015): Acné Juvénile : une Pathologie Fréquente chez les Adolescents Scolarisés d'Afrique Sub-saharienne, Health Sci. Dis: Vol 16 (3) , Pp1-5.

5. Bagatin E., Timpano D., Guadanhim L., Nogueira V., Terzian L., Steiner D., \& Florez M., (2014): Acne vulgaris: prevalence and clinical forms in adolescents from São Paulo, Brazil ,An Bras Dermatol;89(3):428-35.

6. Bettoli V., Zauli S., \& Virgili A., (2015): Is hormonal treatment still an option in acne today? British Journal of Dermatology, 172, 
37-46.

http://www.ncbi.nlm.nih.gov/pubmed/25627824

7. Durai P., \& Nair D., (2015): Acne Vulgaris and Quality of Life Among Young Adults in South India, Indian J Dermatol. 2015 Jan-Feb; 60(1): 33-40.

8. El badry H., (2009): Epidemiology of acne in adolescent, Master thesis in dermatology and andrology, faculty of Medicine, Benha University.

9. El-Hamd M., Nada E., Moustafa M., \& Mahboob-Allah R., (2017): Prevalence of acne vulgaris and its impact of the quality of life among secondary school-aged adolescents in Sohag Province, Upper Egypt, J cosmet Dermatol;1-4.

10. El-Khateeb, E., \&Khafagy N., Abd Elaziz K., \& Shedid A., (2014): prevalence, beliefs, patients' attitudes, severity and impact on quality of life in Egypt ,Public Health Journal;128(6), Pp576-578.

11. Global Burden of Diseases (GBD), (2013): Injuries and Risk Factors:http://www.healthdata.org/sites/default/f iles/files/GBD_2013_Protocol.pdf

12. Hanisah A., Omar K., \& Shah S., (2009): Prevalence of acne and its impact on the quality of life in school-aged adolescents in Malaysia. J Prim Health Care; $1:$ Pp20-5.

13. Hazarika N., \& Rajaprabha R., (2016): Assessment of Life Quality Index Among Patients with Acne Vulgaris in a Suburban Population Indian J Dermatol , Mar-Apr; 61(2): 163-168.

14. Hinge D., Yadav N., Kar S., Madke B., Singh N., \& Krishnan A., (2014): Hospital based comparative study of anxiety and depression in adolescents with or without acne vulgaris, Egyptian Dermatology Online Journal Vol. 10 No 2: 3,Pp1-6.

15. Kartheepan K., Suhail A., Mithuna V., \& Prianka L., (2015): Evaluation of common risk factors of acne teenagers in Batticaloa, 5th International Symposium 2015 , SEUSL, Pp168-171.

16. Kubota Y., Shirahige Y., Nakai K., Katsuura J., Moriue T., \& yoneda K., (2010): Community-based epidemiological study of psychosocial effects of acne in Japanese adolescents, Journal of Dermatology; 37: 617622.

17. Law M., Chuh A., Lee A., \& Molinari N., (2009): Acne prevalence and beyond: acne disability and its predictive factors among Chinese late adolescents in Hong Kong, British
Association of Dermatologists Clinical and Experimental Dermatology, 35, 16-21.

18. Moneam A., Nour Eddin W., Taqi A., Lafta A., Shamssain M., Shahwan M., \& Bloukh S., (2016): the prevalence and factor affecting acne vulgaris among university students, European Journal of Pharmaceutical and Medical Research,3(6), 101-107.

19. Noorbala M., Mozaffary B., \& Noorbala M., (2013): Prevalence of acne and its impact on the quality of life in high school-aged adolescents in Yazd, Iran, Journal of Pakistan Association of Dermatologists 2013;23 (2):168-172.

20. Peric' J., Maksimovi N., Jankovi J., Mijovi B., Relji V., Jankovi S., (2013): Prevalence and quality of life in high school pupils with acne in Serbia, Vojnosanit Pregl ; 70(10): 935939.

21. Safizadeh H., Meymandy S., \& Naeimi A., (2012): Quality of Life in Iranian Patients with Acne, Dermatology Research and Practice, Vol4;P4.

22. Saker A., El-Moez K., Mohammad R., \& Ismail N., (2015): Evaluation of psychiatric morbidity and quality of life in patients with acne vulgaris Egyptian journal of psychiatry; 36 (3) Pp: 144-149.

23. Samanthula H., \& Kodali M., (2013): Acne and Quality of Life- A Study from a Tertiary Care Centre in South India, IOSR Journal of Dental and Medical Sciences, Volume 6, Issue 3, PP 59-62.

24. Shahzad N., Nasir J., Ikram U., Haque A., Qadir A., \& Sohail M., (2011): Frequency and Psychosocial Impact of Acne on University and College Students, Journal of the College of Physicians and Surgeons Pakistan ;21 (7): 442443.

25. Steylaerts C., (2014): Knowledge, Attitudes And Beliefs Of Adolescents Towards Acne, P632 http://www.woncaeurope.org/content/pp632-knowledge-attitudes-and-beliefs-

adolescents-tow-ards-acne

26. Sultana N., (2012): Knowledge on Acne Vulgaris and Menstrual Cycle: A Study on Adolescent Girls, American Supply Association University Review;6 (1 ) ,Pp 265-272.

27. Suvirya S., Singh R., Singh D., \& Agrawal D., (2016): Assessment of self medication practices among medical students in acne vulgaris and patterned baldness in a tertiary care hospital of north India, Indian Journal of applied research; 6(2),Pp680-683.

28. Tasoula E., Gregoriou S., Chalikias J., Lazarou D., Danopoulou I., Katsambas A., \& Rigopoulos D., (2012): The impact of acne 
vulgaris on quality of life and psychic health in young adolescents in Greece. Results of a population survey, An Bras Dermatol ;87(6):862-9.

29. Tuchayi S., Makrantonaki E., Ganceviciene R., Dessinioti C., Feldman S., \& Zouboulis C., (2015): Acne vulgaris , Nat Rev Dis Primers Pp 17;1.

30. Yap F., (2012): Cardiff Acne Disability Index in Sarawak, Malaysia, Ann Dermatol ; 24(2): 158-161. 